\title{
Role of inhibin and activin in the modulation of gonadotropin- and steroid-induced oocyte maturation in the teleost Fundulus heteroclitus
}

\author{
Teresa R Petrino, Gesulla Toussaint and Yu-Wai P Lin*
}

Address: Barry University, School of Natural \& Health Sciences, Miami Shores, Florida 33161, USA

Email: Teresa R Petrino - tpetrino@mail.barry.edu; Gesulla Toussaint - gtoussaint@mail.barry.edu; Yu-Wai P Lin* - plin@mail.barry.edu

* Corresponding author

Published: 5 June 2007

Reproductive Biology and Endocrinology 2007, 5:21 doi:10.1186/1477-7827-5-21

This article is available from: http://www.rbej.com/content/5/I/2I

(C) 2007 Petrino et al; licensee BioMed Central Ltd.

This is an Open Access article distributed under the terms of the Creative Commons Attribution License (http://creativecommons.org/licenses/by/2.0), which permits unrestricted use, distribution, and reproduction in any medium, provided the original work is properly cited.

\begin{abstract}
Background: Activin and inhibin are glycoproteins structurally related to the transforming growth factor-beta superfamily. These peptides were first described as factors that regulate the folliclestimulating hormone (FSH) at the pituitary level. The possible role of inhibin and activin, at the ovarian level, in mediating the stimulatory actions of a Fundulus pituitary extract (FPE) and 17alpha,20beta-dihydroprogesterone (DHP) on oocyte maturation was investigated in this study.
\end{abstract}

Methods: In vitro culture of ovarian follicles and induction of oocyte maturation were carried out in $75 \%$ Leibovitz L- 15 medium. Follicles or denuded oocytes were exposed to FPE, inhibin, activin, ethanol vehicle (control group), or DHP. The competence of the follicles or denuded oocytes to respond to the hormones was assessed by scoring germinal vesicle breakdown (GVBD) used as an indication of the reinitiation of meiosis or oocyte maturation. DHP level was measured by radioimmunoassay.

Results: Addition of FPE promoted the synthesis of DHP by the granulose cells of fully grown ovarian follicles and thus stimulated GVBD in the oocyte. Presence of porcine inhibin did not hinder the synthesis of DHP stimulated by FPE, although it did inhibit the subsequent GVBD in a dosedependent manner, suggesting that the action of inhibin was at the oocyte level. Similarly to the findings with FPE, inhibin also blocked the DHP-induced GVBD in intact follicles, as well as the spontaneous and steroid-induced GVBD of denuded oocyte. Inhibin straightforwardly blocked the response to a low dose of DHP throughout the culture period, while higher doses of the steroid appeared to overcome the inhibitory effect especially at later times. In contrast to inhibin, recombinant human activin A significantly enhanced DHP-induced GVBD in a dose-dependent manner after $48 \mathrm{hr}$, although activin alone was not able to induce GVBD without the presence of the steroid.

Conclusion: Taking together with our previous studies that demonstrate the presence of activin/ inhibin subunits in the ovary of $F$. heteroclitus, these in vitro findings indicate that inhibin and activin are local regulators in the teleost ovary and have opposing effects in modulating oocyte maturation. 


\section{Background}

Activin and inhibin are peptides structurally related to the transforming growth factor- $\beta$ (TGF- $\beta$ ) superfamily of proteins. Inhibins are heterodimeric glycoproteins composed of an $\alpha$-subunit and one of several forms of $\beta$-subunits (e.g. $\beta A$ or $\beta B$ ), resulting in biologically active forms termed inhibin A and inhibin B. Activins are composed of two $\beta$ subunits in any combination [1]. These peptides, found in mammalian follicular fluids, were first described as factors that regulate the follicle-stimulating hormone (FSH) at the pituitary level [2-4]. Cumulative evidence further has established that activin and inhibin function also as local autocrine/paracrine regulators in the gonads. Indeed, these peptides have been implicated in an array of processes in the ovary of mammals including follicle recruitment, granulosa and theca cell proliferation and atresia, steroidogenesis, ovulation, and luteinization [57]. In addition, activin and inhibin have been implicated in oocyte maturation, albeit conflicting evidence has been reported. In this regard, inhibin was shown to have no effect [8] or to inhibit spontaneous division in both cumulus enclosed and denuded oocytes from immature rats [9] and to suppress luteinizing hormone-induced meiosis in follicle-enclosed oocytes of preovulatory rats [8]. Activin was reported to have no effect on oocyte maturation in rats [9] and pig [10], but it has been shown to increase oocyte maturation in immature rats $[11,12]$, monkeys [13], cows [14] and humans [15]. Compared to the information available for mammalian species, less is known about the effect of TGF- $\beta$ related peptides in lower vertebrates. Yet, lower vertebrates offer large numbers of ovarian follicles and therefore they have already served as excellent models for the study of oocyte development and maturation. Indeed, it is well known that in lower vertebrates, oocyte maturation is triggered by a surge of gonadotropin hormones that, acting in the granulose cells, increases the production of progestogens, which action on the oocyte initiates germinal vesicle breakdown (GVBD), or oocyte maturation.

In fish, all major components of the activin-inhibin-follistatin system have been identified [16]. In fact, several studies have shown that inhibin/activin $\beta$-subunits are expressed in goldfish [17-19]; rainbow trout [20]; mullet [21]; zebrafish [22-25]; and killifish [GenBank:AF503775, GenBank:DQ149108, GenBank:DQ387061]. So far, there is evidence for two isoforms of activin $\beta B$ and two isoforms of $\beta A$ in teleost. Furthermore, recombinant goldfish activin $A(\beta A \beta A)$ and activin $B(\beta B \beta B)$ with biological activities were prepared and used for physiological studies [26]. However, while the biological activity of activin has been documented particularly in goldfish at the level of the pituitary regulation of gonadotropin [27], and in zebrafish at the ovarian level [25,28-30], the biological activity of inhibin was not investigated in fish and it is much less understood. Only recently, the complete inhibin $\alpha$-subunit has been cloned or deduced for three species of fish Oncorhynchus mykiss (rainbow trout) [GenBank:AB044566], Fundulus heteroclitus (killifish) [GenBank:AY836522], and Danio rerio (zebrafish) [GenBank:NM 001045204], thus indicating that different assembled dimeric inhibin/activin isoforms may be present in the fish ovary. The aim of this study was to explore and characterize the effects of inhibin on both steroidogenesis and oocyte maturation, or GVBD, in $F$. heteroclitus. In addition, activin was also used in this study, and results show that while activin alone does not initiate GVBD, inhibin and activin have mutually opposing actions to modulate steroid-induced oocyte maturation.

\section{Methods \\ Animal}

Killifish (Fundulus heteroclitus) were collected from salt marshes in the vicinity of St. Augustine, Florida. In the laboratory, fish were maintained in a 25 gal. aquarium at $25^{\circ} \mathrm{C}$ on a $14 / 10 \mathrm{hr}$ light/dark cycle, and were fed three times a day with flake food (TetraMin). The care and use of, as well as all procedures involving, animals have been approved by Barry University's Institutional Animal Care and Use Committee (IACUC), in accordance with the guidelines of the IACUC of the National Institutes of Health (NIH). Fish were anesthetized in 100 ppm 3-aminobenzoic acid ethyl ester methanesulfonate salt (MS222; Sigma, St Louis, MO) before being killed.

\section{Hormones and test substances}

The effect of gonadotropin was tested by using a F. heteroclitus pituitary extract (FPE) prepared as described by [31] at a concentration of 10 pituitary equivalents $/ \mathrm{ml}$ and kept in $100-\mu \mathrm{l}$ aliquots at $-20^{\circ} \mathrm{C}$. Porcine inhibin (Sigma, St. Louis, MO) [with no specification of what form of inhibin (inhibin A or inhibin B or a mixture of both) is present in the preparation], recombinant human activin A [\#1536536(1)], and recombinant human inhibin A [\#NU1-4315] that were supplied by Dr. A. F. Parlow (NIDDK's National Hormone and Pituitary Program and NICHD), were dissolved in culture media, aliquoted, and kept at $-20^{\circ} \mathrm{C}$. FPE, inhibin, and activin aliquots were thawed only once before each experiment and added directly to the culture to obtain the desired concentration. The steroid $17 \alpha, 20 \beta-$ dihydroprogesterone (DHP) was obtained from Steraloids Inc. (Newport, RI), dissolved in ethanol, and added ( $5 \mu \mathrm{l})$ directly to the culture medium.

\section{In vitro culture of ovarian follicles and induction of oocyte maturation}

Ovaries were removed from females and placed in $75 \%$ Leibovitz L-15 medium with L-glutamine (Sigma) containing $100 \mu \mathrm{g}$ gentamicin $/ \mathrm{ml}$, and adjusted to $\mathrm{pH} 7.5$ with $\mathrm{HCl}$ [32]. Intact fully grown prematurational follicles 
(1.2-1.4 $\mathrm{mm}$ in diameter), with visible germinal vesicle, were manually isolated from several ovaries with the aid of fine forceps under a stereomicroscope. F. heteroclitus intact follicles are surrounded by a single layer of granulosa cells external to the vitelline envelope, a vascularized connective tissue sheath or theca, and a simple surface epithelium [33]. Denuded oocytes (without the enveloping follicular cell layers) were obtained by a combination of manual dissection to remove the epithelium and theca layers, and treatment with $\mathrm{Ca}^{2+} / \mathrm{Mg}^{2+}$-free medium to remove the granulosa cells according to [34]. In both cases, intact follicles or denuded oocytes (pooled from 24 ovaries) were washed several times with fresh medium during the isolation procedure. After $1 \mathrm{hr}$ at room temperature $\left(22-25^{\circ} \mathrm{C}\right)$, the atretic oocytes were discarded, and the remaining healthy follicles or oocytes were randomly distributed into 24-well tissue culture trays (Costar No.3525). Each culture well contained 20 intact follicles/ $1 \mathrm{ml}$ L-15 media or 10-14 denuded oocytes depending of the experiment. Follicles or denuded oocytes were then exposed at time zero to FPE, inhibin, activin, ethanol vehicle (control group), or DHP, identified as the maturational inducing substance (MIS) in F. heteroclitus [35]. Incubations were carried out at room temperature for up to $72 \mathrm{hr}$ with no subsequent hormone addition or media change as previously described [31]. The competence of the follicles or denuded oocytes to respond to the hormones was assessed by scoring germinal vesicle breakdown (GVBD) used as an indication of the reinitiation of meiosis or oocyte maturation [36] several times up to 72 hr.

\section{DHP Radioimmunoassay (RIA)}

Previous data for this species [31] have shown that after FPE stimulation the maximum level of steroid production occurs around $24 \mathrm{hr}$ and it is prior to the occurrence of GVBD, which maximum response takes place around 72 hr. Based on these findings, aliquots of culture medium were removed at $24 \mathrm{hr}$ and directly assayed for DHP as previously described [37]; while GVBD was monitored up to $72 \mathrm{hr}$ of culture in the same group of follicles. Radiochemical used as tracer for the DHP radioimmunoassay was obtained from New England Nuclear, Boston, MA, and prepared as described by [31]. Antiserum against DHP was a gift from Dr. Y. Nagahama (Japan).

\section{Statistics}

Data are presented as mean \pm SEM from three or more experiments performed at different dates. Statistical comparisons were conducted by analysis of variance, and the means were subsequently compared by Tukey's test or Hall-Sidak method (all pairwise multiple comparisons). Differences were considered significant if $\mathrm{P} \leq 0.05$.

\section{Results \\ Inhibin effects on oocyte maturation induced by gonadotropin}

It has been well documented that addition of FPE (used as a source of homologous gonadotropin hormones) to $F$. heteroclitus intact follicles cultured in vitro promotes an increase in the synthesis of $17 \alpha, 20 \beta$-dihydroprogesterone (DHP) by the granulosa cells $[33,38]$. This steroid, DHP, has been demonstrated to be the natural maturation inducing substance in this species [35], and it acts directly on the oocyte to induce GVBD. To investigate whether the gonadal peptide inhibin can affect these follicular responses, follicles were incubated with various doses of FPE and purified porcine inhibin. Results (Fig. 1) show that inhibin significantly reduced the number of follicles that underwent GVBD in response to the low dose of FPE (0.025 pit. equiv./ml). The maximum response to FPE in terms of GVBD occurred at $72 \mathrm{hr}$, and a consistent dosedependent inhibitory effect of inhibin was observed throughout the entire incubation period (Fig. 1A). On the other hand, the response of the follicles to a higher dose of FPE (0.25 pit. equiv./ml) was affected to a lesser extent by inhibin (Fig. 1B). Only the higher dose of inhibin (250 IU) caused a significant but not complete inhibition in the GVBD response (Fig. 1B)

In addition, radioimmunoassay of the culture media collected after $24 \mathrm{hr}$ of incubations (Fig. 2), shows an FPE dose-dependent increase in the levels of DHP as previously demonstrated for this species [31]. Addition of inhibin (50-250 IU/ml) in combination with FPE $(0.025$ and 0.25 pit. equiv. $/ \mathrm{ml}$ ) did not significantly affect the steroid levels induced by FPE stimulation. Addition of inhibin simultaneously or one hr previous to the addition of FPE has shown similar results (data not shown).

\section{Inhibin effects on oocyte maturation induced by steroid}

Because FPE induction of GVBD is mediated through the synthesis of DHP, and since the production of this steroid was not affected by inhibin (Fig. 2), the previous experiments suggest that inhibin may affect the process leading to GVBD initiated by the steroid on the oocyte. The next experiments were conducted to investigate the effect of inhibin on the GVBD response to exogenously added DHP. Results (Fig. 3) show that inhibin decreased DHPinduced GVBD during the first $24 \mathrm{hr}$ of culture (Fig. 3A and $3 \mathrm{~B}$ ) at all concentration of DHP used. At this point in time, an apparent and significant dose-dependent inhibition caused by inhibin was observed when it was combined with the lowest dose $(0.001 \mu \mathrm{g} / \mathrm{ml})$ of DHP, while only a partial inhibition (approximately 30\% less GVBD) was observed when inhibin was combined with higher doses of DHP $(0.01$ and $0.1 \mu \mathrm{g} / \mathrm{ml})$ (Fig. 3B). Interestingly, after $40 \mathrm{hr}$ of culture (Fig. 3C), when the maximum GVBD was achieved in response to the various doses of 

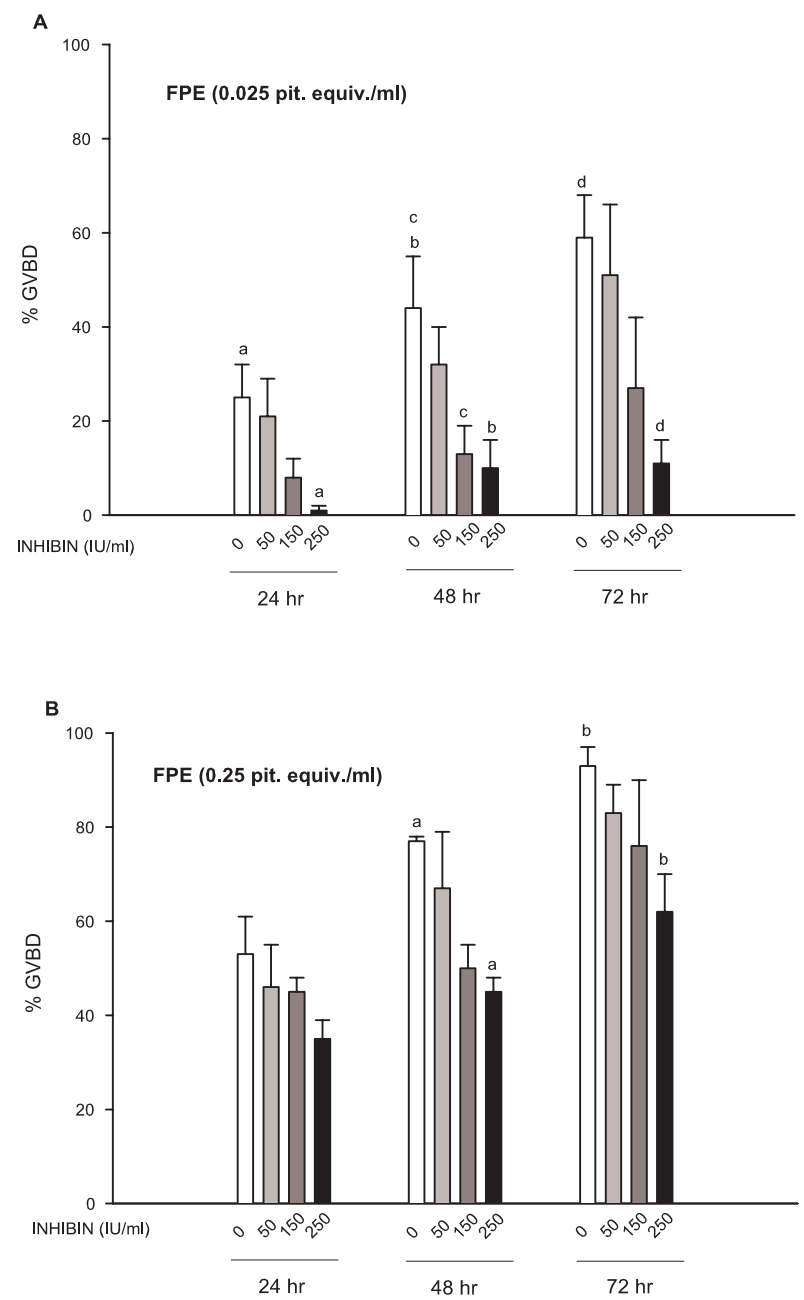

Figure I

Effects of inhibin on FPE-induced oocyte maturation. Isolated ovarian follicles were treated with two doses of FPE: 0.025 pit. equiv. $/ \mathrm{ml}(\mathbf{A})$ or 0.25 pit. equiv. $/ \mathrm{ml}$ (B) alone or in the presence of inhibin $(50-250 \mathrm{lU} / \mathrm{ml})$ as indicated on the abscissa. Inhibin was added simultaneously or I hr previous to FPE addition. Oocyte maturation was monitored by scoring GVBD at 24, 48, and $72 \mathrm{hr}$ of incubation, also indicated on the abscissa. Data are the mean \pm SEM from four different experiments. Same letter indicates significantly different from each other at $P \leq 0.05$.

DHP alone, the inhibitory effect caused by inhibin, which was observed at earlier times, became less evident. No inhibition was observed with any of the inhibin doses (50-250 IU/ml) and the highest doses of DHP $(0.1 \mu \mathrm{g} /$ $\mathrm{ml})$. Only the highest dose of inhibin $(250 \mathrm{IU} / \mathrm{ml})$ partially blocked the response ( $80 \%$ vs. $50 \%$ GVBD) to the middle dose of DHP $(0.01 \mu \mathrm{g} / \mathrm{ml})$. However, the inhibin dose-dependent inhibition only persisted with the lowest

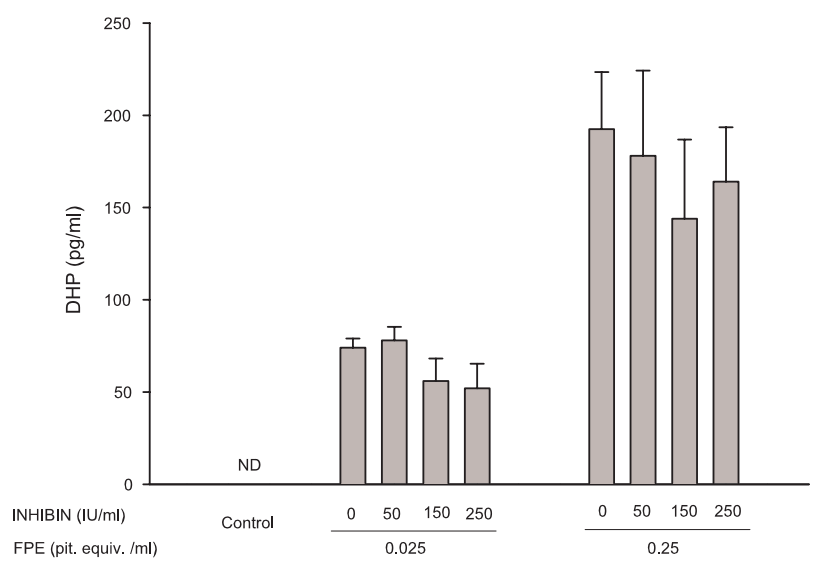

Figure 2

Effects of inhibin on FPE-induced steroid secretion. After 24 $\mathrm{hr}$ of culture with the various treatments described in Fig. I, a fraction of the media was collected for determination of steroid level by radioimmunoassay. Values are the mean \pm SEM from four different experiments. Control = follicles cultured in medium alone without FPE or inhibin. ND = not detectable.

doses of DHP $(0.01 \mu \mathrm{g} / \mathrm{ml})$ throughout the entire culture. In contrast to the inhibitory action on the DHP-induced GVBD observed in the presence of porcine inhibin, we found that addition of recombinant human inhibin $A$ had no effect on GVBD. It did not induce GVBD on its own; neither blocked nor enhanced DHP-induced GVBD (data not shown).

\section{Inhibin effects on denuded oocytes}

To investigate whether the inhibition on the DHPinduced GVBD was the result of a direct interaction of inhibin with the oocyte or whether the inhibitory action was mediated through the follicular cells surrounding the oocyte other than the synthesis of DHP, we treated denuded oocytes (without cellular investments) with inhibin and DHP. In contrast to intact follicles, a higher incidence of GVBD (spontaneous maturation) is observed in F. heteroclitus denuded oocytes without exogenous stimulation [34]. Figure 4 show that inhibin blocked the spontaneous as well as the DHP-induced GVBD of denuded oocytes at both $48 \mathrm{hr}$ and $72 \mathrm{hr}$ of culture. However, the inhibitory effect was less pronounced at the latest time in the group of denuded oocytes induced by a low dose of DHP.

\section{Activin effects on oocyte maturation induced by steroid}

In contrast to inhibin, preliminary experiments indicated that activin may increase the number of oocytes undergoing GVBD. Thus, in order to explore the effect of activin on the DHP-induced GVBD, a sub maximal dose $(0.001 \mu \mathrm{g} /$ 

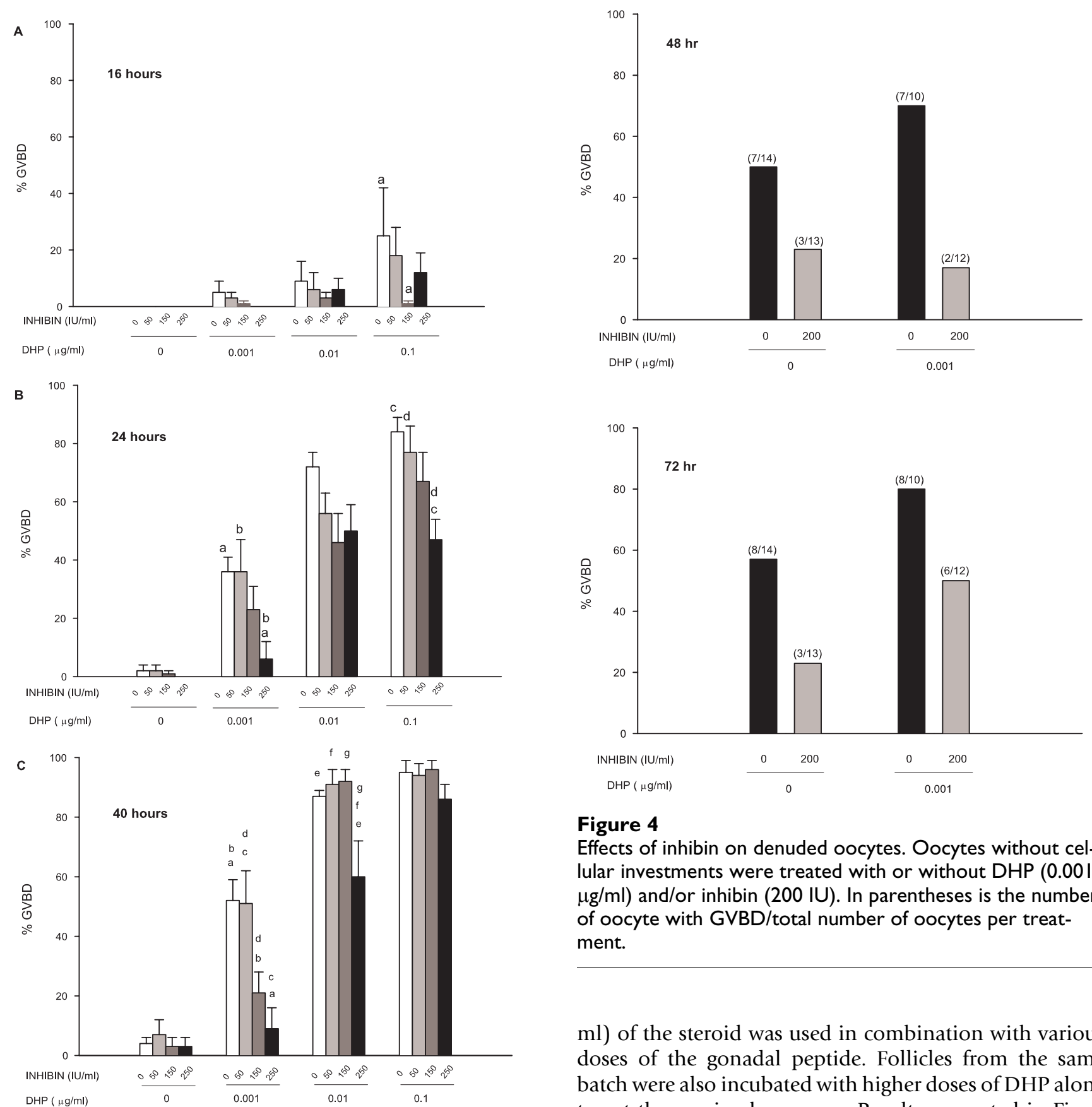

\section{Figure 4}

Effects of inhibin on denuded oocytes. Oocytes without cellular investments were treated with or without DHP $(0.00$ I $\mu \mathrm{g} / \mathrm{ml}$ ) and/or inhibin (200 IU). In parentheses is the number of oocyte with GVBD/total number of oocytes per treatment.

$\mathrm{ml}$ ) of the steroid was used in combination with various doses of the gonadal peptide. Follicles from the same batch were also incubated with higher doses of DHP alone to get the maximal response. Results presented in Fig. 5 show that recombinant human activin A alone did not induce oocyte maturation (GVBD). Moreover, DHPinduced GVBD was not apparently affected by activin during the first $24 \mathrm{hr}$ of culture (Fig. 5). However, activin A significantly enhanced, in a dose-dependent manner, the GVBD induced by a sub maximal dose of steroid $(0.001$ $\mu \mathrm{g} / \mathrm{ml}$ ) after $48 \mathrm{hr}$ of culture. The highest dose of activin used $(250 \mathrm{ng} / \mathrm{ml}$ ) raised the GVBD values to a level similar to those induced by a dose of DHP ten times higher $(0.01 \mu \mathrm{g} / \mathrm{ml})$. 


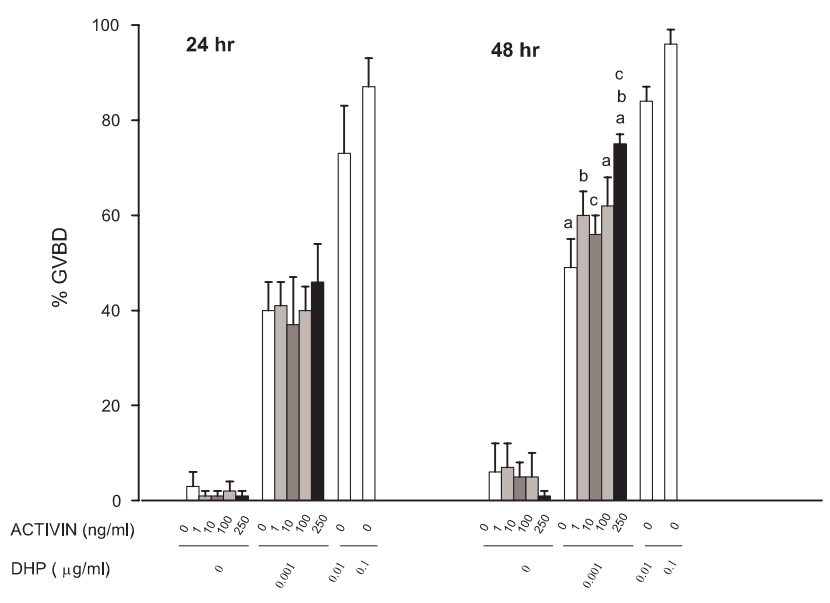

\section{Figure 5}

Effects of activin on DHP-induced steroid secretion. Various doses of human activin $A(0-250 \mathrm{ng} / \mathrm{ml})$, as indicated on the abscissa, were added to the culture media alone or in combination with a sub maximal dose of DHP $(0.001 \mu \mathrm{g} / \mathrm{ml})$. Follicles were also treated with higher doses of DHP (0.0I and $0.1 \mu \mathrm{g} / \mathrm{ml}$ ) alone as positive controls. Oocyte maturation was monitored by scoring GVBD at 24 and $48 \mathrm{hr}$ of incubation. Data are the mean \pm SEM from 5 different experiments. Same letter indicates significantly different from each other at $P \leq 0.05$.

\section{Discussion}

Results from the present study demonstrate that inhibin and activin have mutually opposing effects on modulating the process of oocyte maturation or GVBD induced by steroid in F. heteroclitus, thus implying a local role for these gonadal peptides in the fish ovary. This is supported by the findings that $\alpha$ - and $\beta$-subunits, which are the components of inhibin (dimmer of $\alpha$ and $\beta$ subunits) and activin (dimmer of $\beta \beta$ subunits), are expressed in the ovary of this species [GenBank:AF503775, GenBank:DQ149108, GenBank:AY836522, GenBank:DQ387061].

Similar to other teleost, the process of GVBD in F. heteroclitus is initiated in the prophase I-arrested fully grown oocyte by gonadotropin stimulation of follicular DHP secretion [35]; this steroid (MIS) then acts on the oocyte to trigger the events leading to the reinitiation of meiosis. In the present study, data (Fig. 1) show that inhibin reduced FPE (used as a source of gonadotropin)-induced GVBD. The inhibitory effect on GVBD observed in the presence of inhibin was not only dependent on the inhibin dose but also on the FPE dose used to stimulate oocyte maturation. In effect, inhibin can readily block the stimulation of a low dose of FPE (0.025 pit. equiv./ml) but only moderately affects the response of the follicles to a higher dose of FPE ( 0.25 pit. equiv. $/ \mathrm{ml})$ stimulation, suggesting that the inhibitory effect can be overcome by the action of gonadotropin. Furthermore, the action of inhibin on the FPE stimulation of GVBD is not apparently caused by a decrease in the production of the MIS by the granulosa cells. Data from the radioimmunoassay (Fig. 2) show that the DHP increase that follows FPE stimulation was not altered in the presence of porcine inhibin. It is important to note that medium steroid levels and GVBD were monitored simultaneously in the same set of follicles for each experiment. Since the action of FPE to induce GVBD is mediated through the synthesis of DHP, which was not affected by inhibin, it appears that the inhibin action to suppress GVBD in F. heteroclitus is more likely to occur at the oocyte level rather than to block steroid production by the follicle cells. In addition, we have previously shown that FPE initiates steroidogenesis in the F. heteroclitus ovarian follicles by mobilizing endogenous cholesterol into the mitochondria where the set of enzymes required for the synthesis of DHP are present even in unstimulated follicles [37]. Thus, results from this study indicate that inhibin does not affect the early steroidogenic pathway leading to DHP, the maturational steroid (MIS) in this species. Concomitant to DHP, F. heteroclitus follicles also synthesize testosterone and estradiol [31], which were not measured in this study, and thus we cannot discard the possibility that inhibin may affect other steroidogenic reactions. Interestingly, in a previous study from our laboratory [39] using intact follicles of the amphibian Rana pipiens (leopard frog), we have observed that porcine inhibin significantly blocks both the progesterone synthesis that follows gonadotropin stimulation and the subsequent GVBD. Similar to these findings in amphibians, inhibin has been shown to modulate steroidogenesis in avian species [40], and in mammalian species (for review see $[6,41,42]$. More data are necessary in other species of fish to investigate whether activin and inhibin can also serve as modulators of steroidogenesis in teleost.

Results from Fig. 3 show the dose-dependent inhibition of exogenously added DHP-induced GVBD by inhibin. Similar to the observations made for FPE, the inhibitory effect of inhibin on GVBD was very dependent not only on the inhibin dose but also on the doses of DHP used to trigger the maturational events. Inhibin straightforwardly blocked the response to a low dose of DHP $(0.001 \mu \mathrm{g})$ throughout the culture period, while higher doses of the steroid appeared to overcome the inhibitory effect, especially at later times. The direct action of inhibin on the oocyte was also investigated in denuded oocytes (stripped of all follicular cells). It has been reported that removal of the granulosa cell layer from the oocyte of $F$. heteroclitus frequently triggers the resumption of meiosis in the 
absence of exogenous hormonal stimulation (spontaneous maturation) and thus it was postulated that granulosa cells are somehow responsible for the maintenance of meiotic arrest in non-hormone-treated oocytes [34]. As seen from the results depicted in Fig. 4, fifty percent of denuded oocytes underwent spontaneous maturation and they also responded to exogenously added DHP for the induction of GVBD. Addition of inhibin to denuded oocytes reduced both the spontaneous maturation as well as the maturation induced by DHP, indicating that inhibin acts directly on the oocyte to suppress GVBD. These results support the hypothesis postulated for other species that inhibin can act as a negative modulator of oocyte maturation. Indeed, bovine inhibin was reported to inhibit spontaneous oocyte maturation in both cumulus enclosed and denuded rat oocytes [9]; ovine inhibin and transforming growth factor beta (TGF $\beta$ ) partially inhibited luteinizing hormone (LH)-induced meiosis in rat follicle-enclosed oocytes [8]; and porcine inhibin inhibited both the gonadotropin-stimulated progesterone production and the subsequent oocyte maturation in the amphibian Rana pipiens [39]. However, Wu et al. [30] have reported that recombinant human inhibin A stimulates GVBD in zebrafish follicles. Similarly to the zebrafish study, maturation-enhancing effects of recombinant human inhibin A were reported for primates [13]. We have also tried incubations of $F$. heteroclitus ovarian follicles with recombinant human inhibin $\mathrm{A}$ and found that it did not induce GVBD on its own; neither has it had an enhancement nor inhibitory effect on DHP-induced oocyte maturation (data not shown). Kagawa et al. [43] also reported that recombinant human inhibin A has no effect on oocyte maturation of another teleost, the red seabream. Since not all the forms of inhibin are available to specifically investigate their autocrine/paracrine role, the apparent conflicting results may be related to both the variations in the form of inhibin present in the preparations, as previously suggested by other researchers, and the species' specific responsiveness to the various forms of gonadal peptides. Thus, taking together all of these findings, it appears that recombinant human inhibin A may have a stimulatory effect in terms of oocyte maturation in some species, while the inhibin used in the other studies, including this one, may have contained a mixture of both inhibin A and inhibin B. Then, we can speculate that inhibin B may be responsible for the inhibition observed on oocyte maturation.

Regarding the activin effects, our findings are consistent with those reported for zebrafish [30] in that recombinant human activin A has a stimulatory effect on $F$. heteroclitus oocyte maturation. However, in contrast to the zebrafish, recombinant human activin $\mathrm{A}$ alone did not induce oocyte maturation (GVBD) in F. heteroclitus. Nevertheless, recombinant human activin A significantly enhanced
DHP-induced GVBD in a dose-dependent manner after $48 \mathrm{hr}$ (Fig. 5). No activin effect was observed during the first $24 \mathrm{hr}$ of culture indicating that activin does not affect the time course of oocyte maturation induced by the steroid, but rather it increases the number of the oocytes undergoing GVBD. In effect, the highest dose of activin used $(250 \mathrm{ng} / \mathrm{ml})$ in combination with a low dose of DHP $(0.001 \mu \mathrm{g} / \mathrm{ml})$ raised the GVBD values to a level similar to those induced by a dose of steroid alone ten times higher $(0.01 \mu \mathrm{g} / \mathrm{ml})$. These results support the hypothesis proposed by Pang and Ge [44] that activin may act directly on the oocyte to enhance the maturational competence or responsiveness to DHP in zebrafish. Similarly, it was proposed that activin enhances the oocyte developmental competence in mammals [7]. Activins and other members of the TGF $\beta$ initiate their biological actions by interacting with transmembrane receptors named receptor serine kinases (RSKs) [45]. The presence of type I, type II, and type IIB receptors has been demonstrated in a variety of tissues including the ovary, testis, and brain in goldfish and zebrafish [16], thus giving support for the actions of inhibin and activin molecules in teleosts.

$F$. heteroclitus, have group-synchronous ovaries, in which all sizes of vitellogenic follicles are present at any time, and clutches of follicles from a population of oocytes in late vitellogenic stages, are periodically recruited into maturation $[46,47]$. In order to maintain the integrity of the follicular sequence in this species, it was postulated that local factors other than gonadotropins or steroids might regulate follicle selection into maturation by modulating the oocyte sensitivity to the MIS [48]. Taken together, the in vitro findings from this study indicate that inhibin and activin, which have opposing effects on modulating oocyte maturation and are expressed in the F. heteroclitus ovary, are good candidates to serve as local factors in this respect.

\section{Conclusion}

The inhibitory action of inhibin on the FPE stimulation of oocyte maturation was not caused by a decrease in the production of the steroid DHP (the natural inducer of GVBD). Inhibin appears to act directly on the oocyte to block the spontaneous maturation of denuded oocytes, as well as the DHP-induced maturation of intact follicles and denuded oocytes. The inhibitory effect on oocyte maturation was dependent not only on the dose of inhibin, but also on the dose of the stimulatory hormones. High dose of inducing hormone (FPE or DHP) was able to overcome the inhibin inhibition. Activin, on the other hand, significantly enhances DHP-induced GVBD, but does not induce oocyte maturation on its own. Hence, both inhibin and activin are paracrine regulators in the teleost ovary and have opposing effects in the modulation of oocyte maturation. 


\section{Competing interests}

The author(s) declare that they have no competing interests.

\section{Authors' contributions}

TRP participated in the design of the study, performed oocyte culture, carried out the statistical analysis and wrote the manuscript. YWL conceived of the study, and participated in its design and coordination, performed the radioimmunoassay (RIA) and helped to draft the manuscript. GT carried out oocyte culture and RIA. All authors read and approved the final manuscript.

\section{Acknowledgements}

This research was supported by an NIH-MBRS SCORE (SO6 GM 45455) grant awarded to Y.-W. P. Lin. GT was supported by NIH-MBRS RISE (R25 GM 059244) grant. We thank Sr. Dorothy M. Jehle, OP, PhD, for editorial assistance in the preparation of this manuscript.

\section{References}

I. Ying SY: Inhibins, activins, and follistatins: gonadal proteins modulating the secretion of follicle-stimulating hormone. Endocr Rev 1988, 9:267-293.

2. Rivier J, Spiess J, McClintock R, Vaughan J, Vale W: Purification and partial characterization of inhibin from porcine follicular fluid. Biochem Biophys Res Commun 1985, I33:120-127.

3. Ling N, Ying SY, Ueno N, Esch F, Denoroy L, Guillemin R: Isolation and partial characterization of a Mr 32,000 protein with inhibin activity from porcine follicular fluid. Proc Natl Acad Sci U S A 1985, 82:7217-722I.

4. de Jong FH, Robertson DM: Inhibin: 1985 update on action and purification. Mol Cell Endocrinol 1985, 42:95-103.

5. Phillips DJ: Activins, inhibins and follistatins in the large domestic species. Domest Anim Endocrinol 2005, 28: I-16.

6. Mather JP, Moore A, Li RH: Activins, inhibins, and follistatins: further thoughts on a growing family of regulators. Proc Soc Exp Biol Med 1997, 21 5:209-222.

7. Knight PG, Glister C: Local roles of TGF-beta superfamily members in the control of ovarian follicle development. Anim Reprod Sci 2003, 78: 165-183.

8. Tsafriri A, Vale W, Hsueh AJ: Effects of transforming growth factors and inhibin-related proteins on rat preovulatory graafian follicles in vitro. Endocrinology 1989, I 25: | 1857-1862.

9. O WS, Robertson DM, de Kretser DM: Inhibin as an oocyte meiotic inhibitor. Mol Cell Endocrinol 1989, 62:307-3।I.

10. Coskun S, Lin YC: Effects of transforming growth factors and activin-A on in vitro porcine oocyte maturation. Mol Reprod Dev 1994, 38: 153-159.

II. Itoh M, Igarashi M, Yamada K, Hasegawa Y, Seki M, Eto Y, Shibai H: Activin A stimulates meiotic maturation of the rat oocyte in vitro. Biochem Biophys Res Commun 1990, I66:1479-I484.

12. Sadatsuki M, Tsutsumi O, Yamada R, Muramatsu M, Taketani Y: Local regulatory effects of activin $A$ and follistatin on meiotic maturation of rat oocytes. Biochem Biophys Res Commun 1993, 196:388-395.

13. Alak BM, Smith GD, Woodruff TK, Stouffer RL, Wolf DP: Enhancement of primate oocyte maturation and fertilization in vitro by inhibin A and activin A. Fertil Steril 1996, 66:646-653.

14. Stock AE, Woodruff TK, Smith LC: Effects of inhibin $A$ and activin A during in vitro maturation of bovine oocytes in hormone- and serum-free medium. Biol Reprod 1997, 56: I 559-I 564.

15. Alak BM, Coskun S, Friedman Cl, Kennard EA, Kim MH, Seifer DB: Activin A stimulates meiotic maturation of human oocytes and modulates granulosa cell steroidogenesis in vitro. Fertil Steril 1998, 70:1 I26-1130.

16. Ge W: Roles of the activin regulatory system in fish reproduction. Can J Physiol Pharmacol 2000, 78: 1077-1085.

17. Calp MK, Matsumoto JA, Van Der KG: Activin and transforming growth factor-beta as local regulators of ovarian steroidogenesis in the goldfish. Gen Comp Endocrinol 2003, 132:142-150.
18. Ge W, Gallin WJ, Strobeck C, Peter RE: Cloning and sequencing of goldfish activin subunit genes: strong structural conservation during vertebrate evolution. Biochem Biophys Res Commun 1993, | 193:7||-7|7.

19. Ge W, Cook H, Peter RE, Vaughan J, Vale W: Immunocytochemical evidence for the presence of inhibin and activin-like proteins and their localization in goldfish gonads. Gen Comp Endocrinol 1993, 89:333-340.

20. Tada T, Endo M, Hirono I, Takashima F, Aoki T: Differential expression and cellular localization of activin and inhibin mRNA in the rainbow trout ovary and testis. Gen Comp Endocrinol 2002, 125:142-149.

21. Mousa MA, Mousa SA: Immunohistochemical localization of inhibin and activin-like proteins in the brain, pituitary gland, and the ovary of thin-lipped grey mullet, Liza ramada (Risso). Gen Comp Endocrinol 2003, 132:434-443.

22. DiMuccio T, Mukai ST, Clelland E, Kohli G, Cuartero M, Wu T, Peng $C$ : Cloning of a second form of activin-betaA cDNA and regulation of activin-betaA subunits and activin type II receptor mRNA expression by gonadotropin in the zebrafish ovary. Gen Comp Endocrinol 2005, I 43:287-299.

23. Wang $Y$, Ge W: Spatial expression patterns of activin and its signaling system in the zebrafish ovarian follicle: evidence for paracrine action of activin on the oocytes. Biol Reprod 2003, 69:1998-2006.

24. Wang Y, Ge W: Involvement of cyclic adenosine 3',5'-monophosphate in the differential regulation of activin betaA and betaB expression by gonadotropin in the zebrafish ovarian follicle cells. Endocrinology 2003, I 44:49|-499.

25. Wang $\mathrm{Y}, \mathrm{Ge} \mathrm{W}$ : Developmental profiles of activin betaA, betaB, and follistatin expression in the zebrafish ovary: evidence for their differential roles during sexual maturation and ovulatory cycle. Biol Reprod 2004, 71:2056-2064.

26. Ge W, Miura T, Kobayashi H, Peter RE, Nagahama Y: Cloning of cDNA for goldfish activin beta $B$ subunit, and the expression of its mRNA in gonadal and non-gonadal tissues. J Mol Endocrinol 1997, 19:37-45.

27. Yam KM, Yoshiura Y, Kobayashi M, Ge W: Recombinant goldfish activin $B$ stimulates gonadotropin-lbeta but inhibits gonadotropin-Ilbeta expression in the goldfish, Carassius auratus. Gen Comp Endocrinol 1999, I 16:81-89.

28. Pang $\mathrm{Y}, \mathrm{Ge} \mathrm{W}$ : Activin stimulation of zebrafish oocyte maturation in vitro and its potential role in mediating gonadotropininduced oocyte maturation. Biol Reprod 1999, 61 1:987-992.

29. Pang $Y, \mathrm{Ge} W$ : Epidermal growth factor and TGFalpha promote zebrafish oocyte maturation in vitro: potential role of the ovarian activin regulatory system. Endocrinology 2002, 143:47-54.

30. Wu T, Patel H, Mukai S, Melino C, Garg R, Ni X, Chang J, Peng C: Activin, inhibin, and follistatin in zebrafish ovary: expression and role in oocyte maturation. Biol Reprod 2000, 62:1585-1592.

31. Lin YW, Lamarca MJ, Wallace RA: Fundulus heteroclitus gonadotropin(s). I. Homologous bioassay using oocyte maturation and steroid production by isolated ovarian follicles. Gen Comp Endocrinol 1987, 67:126-141.

32. Greeley MS Jr., Calder DR, Taylor MH, Hols H, Wallace RA: Oocyte maturation in the mummichog (Fundulus heteroclitus): effects of steroids on germinal vesicle breakdown of intact follicles in vitro. Gen Comp Endocrinol 1986, 62:28I-289.

33. Petrino TR, Greeley MS Jr., Selman K, Lin YW, Wallace RA: Steroidogenesis in Fundulus heteroclitus. II. Production of 17 alpha-hydroxy-20 beta-dihydroprogesterone, testosterone, and 17 beta-estradiol by various components of the ovarian follicle. Gen Comp Endocrinol 1989, 76:230-240.

34. Greeley Jr MS, Begovac PC, Wallace RA: Removal of enveloping follicle cells can trigger resumption of meiotic maturation in Fundulus heteroclitus oocytes. J Exp Zool I987, 244: I77-I80.

35. Petrino TR, Lin YW, Netherton JC, Powell DH, Wallace RA: Steroidogenesis in Fundulus heteroclitus $V$.: purification, characterization, and metabolism of 17 alpha, 20 beta-dihydroxy-4pregnen-3-one by intact follicles and its role in oocyte maturation. Gen Comp Endocrinol 1993, 92: I-I5.

36. Wallace RA, Selman K: Oogenesis in Fundulus heteroclitus. I. Preliminary observations on oocyte maturation in vivo and in vitro. Dev Biol 1978, 62:354-369. 
37. Petrino TR, Lin YW, Wallace RA: Steroidogenesis in Fundulus heteroclitus. I. Production of 17 alpha-hydroxy, 20 beta-dihydroprogesterone, testosterone, and 17 beta-estradiol by prematurational follicles in vitro. Gen Comp Endocrinol 1989, 73:147-156.

38. Lin YWP, Greeley MS Jr., Wallace RA: Fundulus heteroclitus gonadotropin(s) 2. Year-round husbandry of animals with active pituitaries and responsive follicles. Fish Physiol Biochem 1989, 6:139-148.

39. Lin YW, Petrino T, Landin AM, Franco S, Simeus I: Inhibitory action of the gonadopeptide inhibin on amphibian (Rana pipiens) steroidogenesis and oocyte maturation. J Exp Zool 1999, 284:232-240.

40. Rombauts L, Vanmontfort D, Decuypere E, Verhoeven G: Inhibin and activin have antagonistic paracrine effects on gonadal steroidogenesis during the development of the chicken embryo. Biol Reprod 1996, 54: I 229-1 237.

41. Ackland JF, Schwartz NB, Mayo KE, Dodson RE: Nonsteroidal signals originating in the gonads. Physiol Rev 1992, 72:731-787.

42. Peng C, Mukai ST: Activins and their receptors in female reproduction. Biochem Cell Biol 2000, 78:26I-279.

43. Kagawa H, Kobayashi M, Hagesawa $Y$, Aida K: Insulin and insulinlike growth factors I and II induce final maturation of oocytes of red seabream, Pagrus major, in vitro. Gen Comp Endocrinol 1994, 95:293-300.

44. Pang $Y, G e$ W: Gonadotropin and activin enhance maturational competence of oocytes in the zebrafish (Danio rerio). Biol Reprod 2002, 66:259-265.

45. Vale W, Wiater E, Gray P, Harrison C, Bilezikjian L, Choe S: Activins and inhibins and their signaling. Ann N Y Acad Sci 2004, 1038: | $42-147$.

46. Hsiao SM, Greeley Jr MS, Wallace RA: Reproductive cycling in female Fundulus heteroclitus. Biol Bull 1994, 186:27I-284.

47. Taylor $\mathrm{MH}$, DiMichele $\mathrm{L}$ : Ovarian changes during the spawning cycle of Fundulus heteroclitus. Copeia 1980, 1980: I I8-125.

48. Cerdá J, Calman BG, LaFleur Jr GJ, Limesand S: Pattern of vitellogenesis and follicle maturational competence during the ovarian follicular cycle of Fundulus heteroclitus. Gen Comp Endocrinol 1996, 103:24-35.

Publish with Bio Med Central and every scientist can read your work free of charge

"BioMed Central will be the most significant development for disseminating the results of biomedical research in our lifetime. "

Sir Paul Nurse, Cancer Research UK

Your research papers will be:

- available free of charge to the entire biomedical community

- peer reviewed and published immediately upon acceptance

- cited in PubMed and archived on PubMed Central

- yours - you keep the copyright
BioMedcentral 